\title{
Strategies to Enhance College Student Happiness Index
}

\author{
Yun-Heng ZHENG and Xin-Hua YAO* \\ Beihua University ,Jilin, China \\ *Corresponding author: Xin-Hua YAO
}

Keywords: Happiness, Strategy, Index, College students

\begin{abstract}
College Student happiness is not only affected by internal subjective factors, but also by external objective factors. Such as personality, self-efficacy, cognitive model, coping style and other subjective factors, health status, economic status, family status, life events, social relations and other objective factors, factors mentioned above will affect the subjective well-being of College students. Happiness is the basic purpose and final pursuit of life of college students. How to face the phenomenon of lack of happiness index among college students has become an important topic of promoting the well-being of college students in higher education, therefore, this paper proposed some effective strategies to enhance college student happiness index by means of survey analysis.
\end{abstract}

\section{Introduction}

Higher education should not only cultivate the correct concept of happiness, but also to actively guide students to enhance the level of happiness, strengthen their self-cultivation, cultivate a good attitude in life practice, the pursuit of happiness, happiness and enjoy the happiness in the physical and mental harmony, a truly meaningful happy life. For college students, their own health, self-worth, self emotion, emotion and family and interpersonal factors are very important to their well-being. To sum up, the health factor is the foundation, the value factor is the key, the family factor is the key, the interpersonal factor is the adjustment, and the emotional factor is the embodiment.

\section{The main factors affecting the well-being of College Students}

Health influencing factors. Health is divided into mental health and physical health. Health is an important foundation for happiness. A healthy body can reduce disease and lack of energy brings troubles, the health of the person on the other hand has good exercise habits, this is a way to vent negative emotions, but also increase exchanges between strangers and the way to the birth of happiness means interest.

Values influence factors. Under the impact of the market economy and the influence of Western values, there are some deviations from the university students' Outlook on happiness,

Hedonism, money worship, and extreme individualism tend to rise. The survey found that $70.3 \%$ of the students think that "life how much happiness and money have a certain relationship, 10.5\% of the students that the happiness of life and how much money is proportional to, or even $7 \%$ of the students believe that the greatest happiness of life is the" high social position and a certain economic strength". When the pursuit of money and material enjoyment to put a more and more important role, some university students' philosophy of life from idealism into "Existentialism"; in the happiness of the way, the students hand recognized "happiness cannot do without down-to-earth work and create" this view, another it emphasizes the opportunities and connections in determining 
whether a person is happy or not on a large proportion, to seek opportunities and establish contacts and even a few people deliberately plan, in order to pursue their own happiness by unfair means, harm others and social interests.

Family influence factors. The family is the cradle of the college students, ideological enlightenment, relying on the development of emotion, family environment on the well-being of college students have a significant impact, especially in parenting style is directly affect the development of children's sense of happiness. Parents are the first teachers of their children. Warmth and rearing style of parents and children's well-being positivelycorrelated, refused to deny parenting and child well-being was negatively correlated, influence of parents' preference for children's emotional satisfaction greatly, mother's educational level, family structure have some effects on the children's happiness. Thus, the family environment has a significant impact on children's happiness, good family environment and conditions, reasonable parenting style is not only the direct factors affecting the well-being of children, but also by the influence of children's self-esteem and personality factors which affects their sense of happiness.

Interpersonal factors. People are always living in a certain group, and they have the desire to gain recognition and support from others in the community. Interpersonal relationships, therefore, have an important effect on people's well-being. From family, friends, teachers, classmates and other support, by providing material support or other substantive information on help for emotional support, can increase the students' sense of security, a sense of belonging, self-esteem, positive emotions, which makes them more likely to experience happiness and happiness, especially when they face stressful life events, but also can prevent or alleviate the stress response, thereby inhibiting negative emotions; on the other hand, the lack of support and recognition of family, friends, teachers, classmates and other negative emotions, they will produce more, thus reducing their happiness.

\section{Improve the well-being of college students Countermeasures}

To build a harmonious family atmosphere. The source of social harmony in the family harmony, the harmony of the family comes from parents, parents and children. So the construction of harmonious family harmony, is the responsibility of every family in common. Parents should make clear their responsibilities, provide the material basis for the harmony of the family of God and a fine example. As a child, should know how to appreciate many parents, communication with parents, respect their parents' choice.

Pay attention to the cultivation of learning ability. The new period college students with a solid professional foundation, good learning ability, can in the fierce competition in the talent shows itself in the workplace, become a compound talents in today's society. The core competitiveness is "learning ability", namely the learning ability of college students to fully understand the importance of learning, scientific learning method, improve the efficiency of learning, rest, in order to effectively improve the learning ability; to actively participate in social practice, through education, voluntary service, policy propaganda, research and other forms of grassroots services, actively integrate individual talent and social services, "establishing the scientific development view of the growth of Contemporary College Students and values" in social practice experience the joy of learning, cultivate the ability of self-study.

Strengthen the mental health education work. Colleges and universities should gradually improve their psychological counseling services, building a professional mental health counseling teachers and classes of mental health care team, to understand the health status of students thinking in time through psychological health care team, the first time to guide students to make better use of 
resources to solve the problem of school psychological counseling, the cultivation of the consciousness of students encountered confusion or other psychological problems of professional psychological counseling services actively seek. Colleges and universities should pay attention to ideological and political education team (mainly by counselors, teachers, teachers of Ideological and political theory courses form) the work of engineering and home school students to talk, understand and guide the students to rationally solve the problem, with particular emphasis on single parent families and students mental health problems care, care work, pay attention to students' psychological counseling and psychological problems of prevention work.

Pay attention to ideological education, set up the ideal of life. College students should be clear about the goal of life, establish lofty ideals, to actively the construction of socialist modernization, to realize the great rejuvenation of the Chinese nation "Chinese dream" as their ideal of life; employment oriented to improve the comprehensive ability to adapt to the fierce employment requirements, the pursuit of knowledge as a power forward, a solid foundation for the better employment lay. At the same time, and actively carry out all kinds of community sports activities in Colleges and universities should build a campus, second class platform, "the socialist core value system into the whole process of the cultivation of College Students' values in college life, encourage students to actively participate in the research and innovation of college students, improve the students' organization, communication, communication and professional innovation ability. To the new senior college students in the new era to shape the moral, wisdom, body, beauty and all-round development of the Compound talents

Happiness is a process, but also a state. In addition to having the ability to perceive happiness, happiness should include the ability to create happiness. The ability to perceive happiness and the ability to create happiness are two important aspects of a person's happiness. Only in the process of creation can college students feel real happiness, and only when they feel real happiness can they realize the value of creating happiness

\section{Acknowledgements}

This paper is one of achievements of Jilin Province Education Science "13th Five-Year "general program "experience - cognition"education model research based on survey on the well-being of post - 95 students ( GH170065)

\section{References}

[1] Hong Baoling, Liu Wei. Analysis of subjective well-being of college students and strategies for training college students [J], adult education in China, 2010 (2): 5859.

[2] Chai Sufang, survey and analysis, seven colleges and universities nationwide college students of Ideological \& theoretical education, [J], 2012.1

[3] Li Chun. Study on the lack of College Students' happiness and the development of education and happiness ability [J]. education and profession, 2013 (24): 77-78.

[4] Luo Xueli. Investigation and Reflection on Contemporary College Students' happiness -- Taking Hubei College of Arts and sciences as an example, [J]. Journal of Xichang College (SOCIAL SCIENCE EDITION), 2013,25 (3): 115-118.

[5] Zou Guozhen, Li Guoyue. Influence factors and promotion strategies of College Students' sense of happiness. [J]. research on Ideological and political education, 2012,28 (3): 118-121. 
[6] Feng Huimin, Liu Xiaofang, Li Ruxuan. Investigation and comparison of the well-being of female students across the Taiwan Straits [J]. Journal of Wuhan University (PHILOSOPHY AND SOCIAL SCIENCES), 2014 (1): 117-123. 